\title{
Understanding psoriasis: Role of miRNAs (Review)
}

\author{
TEODORA LARISA TIMIS* ${ }^{*}$ and REMUS IOAN ORASAN* \\ Department of Physiology, 'Iuliu Hatieganu' University of Medicine and Pharmacy, 400006 Cluj-Napoca, Romania
}

Received June 7, 2018; Accepted September 4, 2018

DOI: $10.3892 /$ br.2018.1146

\begin{abstract}
Psoriasis is a chronic, immune-mediated inflammatory skin disease, with a multifactorial etiology and important immunologic, genetic and environmental components. Psoriasis vulgaris represents its most common form, with a variable prevalence across the globe. Although its pathogenesis remains to be fully elucidated, a lack of balance in the epigenetic network has been shown to trigger certain elements of this disease, possibly altering its outcome. MicroRNAs are small non-coding RNA molecules involved in RNA-silencing and the post-transcriptional regulation of gene expression, which also appear to mediate the immune dysfunction in psoriasis. Although microRNA research is a new field in dermatology and psoriasis, there is rapidly accumulating evidence for its major contribution in the pathogenesis of chronic inflammatory conditions, including psoriasis and other dermatological disorders. Furthermore, circulating miRNAs identified in patients' blood samples have been identified as promising biomarkers of diagnosis, prognosis or treatment response. Extended investigations in this field are required, as until now, the exact involvement of miRNAs in psoriasis have remained to be entirely elucidated. This short review highlights a number of the roles of miRNAs found in different stages of psoriasis.
\end{abstract}

Correspondence to: Dr Teodora Larisa Timis, Department of Physiology, 'Iuliu Hatieganu' University of Medicine and Pharmacy, 1 Clinicilor Street, 400006 Cluj-Napoca, Romania

E-mail: doratimis@gmail.com

*Contributed equally

Abbreviations: TNF- $\alpha$, tumor necrosis factor- $\alpha$; IFN- $\gamma$, interferon- $\gamma$; TGF- $\beta$, transforming growth factor- $\beta$; IL, interleukin; miRNA, microRNA; pri-miRNA, primary miRNA; SMAD7, mothers against decapentaplegic homolog 7; TIMP-3, metalloproteinase inhibitor 3; ADAM17, a disintegrin and metalloprotease 17; NF-кB, nuclear factor $\kappa$-light-chain-enhancer of activated B cells; IGF-1R, insulin-like growth factor 1 receptor; TLR, Toll-like receptor; CCL, chemokine ligand; IRAK1, interleukin 1 receptor-associated kinase 1; TRAF6, TNF receptor-associated factor 6; PTEN, phosphatase and tensin homolog; VEGF, vascular endothelial factor; AKT, $\alpha$-serine/ threonine-protein kinase; PI3K, phosphoinositide 3-kinase; $\mathrm{HaCaT}$, immortalized nontumorigenic human epidermal cells

Key words: microRNA, psoriasis, immune system, keratinocytes

\section{Contents}

1. Introduction

2. MicroRNAs involved in psoriasis

3. Conclusion

\section{Introduction}

Psoriasis is an inflammatory, T-cell-mediated skin disease possessing a variable distribution, severity and course from patient to patient (1). It affects $\sim 3 \%$ of the world population, although the regional prevalence may differ (2). Immunologically it is characterized by the intense proliferation and aberrant differentiation of keratinocytes, and the infiltration of the epidermis with lymphocytes and neutrophils wherein T-cells, dendritic cells and certain inflammatory cytokines act as the principal actors (3-6). The major inflammatory molecules characteristic for psoriasis are tumor necrosis factor- $\alpha$ (TNF- $\alpha$ ), interferon- $\gamma$ (IFN- $\gamma$ ), transforming growth factor- $\beta$ (TGF- $\beta$ ) and interleukins, including interleukin (IL)-1, IL-17 and IL-22 (4,5). In addition to immunological involvement, psoriasis has been shown to possess genetic susceptibility and is susceptible to environmental triggers $(3,7)$. The key role of microRNAs (miRNAs) in regulating the hyperproliferation, differentiation of keratinocytes, apoptosis and atypical immune activation in psoriasis has been widely discussed $(5,7)$. miRNAs are small non-coding RNAs derived from larger primary RNA transcripts in the human genome, with significant roles in post-transcriptional gene expression regulation (8). miRNAs are transcribed by polymerase II or III into primary precursor transcripts, which are first processed in the nucleus by Drosha and DiGeorge syndrome critical region 8 enzymes (9). Following nuclear processing, a precursor miRNA is then transported by the exportin 5-Ran GTPase shuttle system into the cytoplasm for final processing by Dicer and RNase III-like endonuclease in order to obtain mature miRNAs (10). Subsequently, an RNA-induced silencing complex is formed, which regulates gene expression by causing target mRNA degradation or translation repression (9) (Fig. 1). Previous studies have shown that there are multiple dysregulated miRNAs in psoriasis (3).

In the following sections, the miRNAs most frequently associated with psoriasis are presented, according to their tendency to be either upregulated or downregulated, and their presence within the blood or diseased tissue samples. These miRNAs include: miR-21, which maintains skin inflammation 


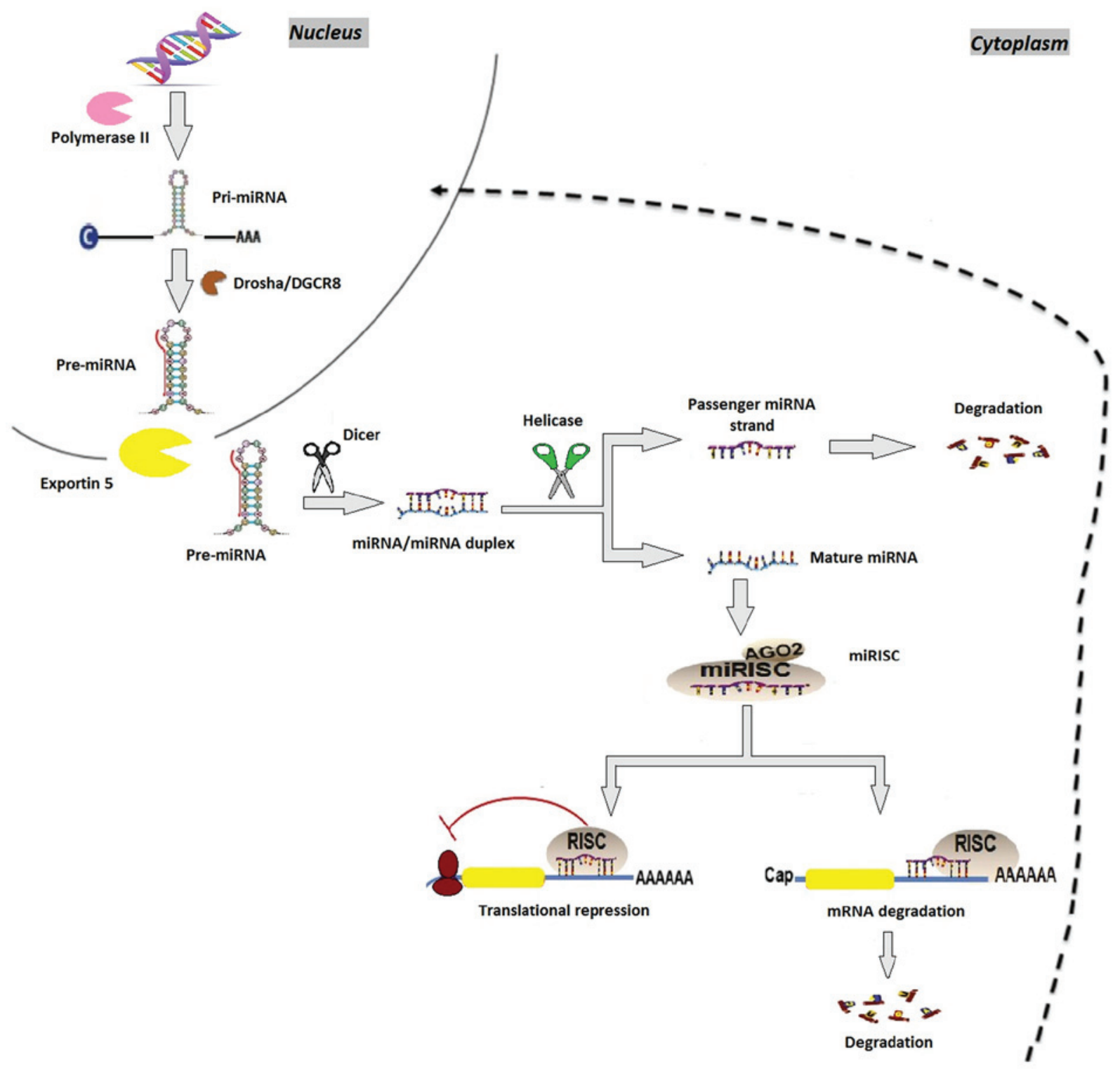

Figure 1. miRNA biosynthesis. miRNA genes are transcribed by RNA polymerase II as pri-miRNAs, which are subsequently processed by Drosha, resulting in pre-miRNA. Pre-miRNAs are then transported by the exportin 5-Ran GTPase shuttle system into the cytoplasm where they are cleaved by another RNase family enzyme (Dicer), resulting in the miRNA/miRNA duplex. During this phase, Dicer interacts with AGO2 proteins generating the RISC. Immediately following this, one strand of the miRNA duplex is removed while the single stranded miRNA remains in the complex and interacts with the $3^{\prime}$ untranslated region of target mRNA genes, inducing posttranscriptional silencing and translational repression. miRNA, microRNA; pri-miRNA, primary RNA; pre-miRNA, miRNA precursor; DGCR8, DiGeorge syndrome critical region 8; AGO2, argonaute 2; RISC, RNA-induced silencing complex.

in psoriasis patients; miR-31, which enhances the production inflammatory cytokines and chemokines via TNF- $\alpha$; miR-146, which has a marked correlation with the expression of IL-17; miR-155, leading to the production of TNF- $\alpha$; miR-203, which induces epithelial differentiation and supresses skin immune responses; miR-99, which inhibits keratinocyte differentiation by targeting insulin-like growth factor-1 receptor (IGF-1R); miR-125, which supresses cell proliferation; miR-197, which decreases the proliferation and migration of keratinocytes; and miR-520, which supresses the mitotic entry and proliferation of keratinocytes (3).

\section{MicroRNAs involved in psoriasis}

$m i R-21$. miR-21 is overexpressed in psoriasis, is found in psoriatic skin lesions, psoriatic epidermal cells, dermal
$\mathrm{T}$ cells and in blood samples, and it has a major role in psoriasis (11). It activates mothers against decapentaplegic homolog 7, which is an antagonist of the TGF- $\beta 1$ signaling pathway $(11,12)$. In psoriatic patients, the expression of TGF- $\beta$ is higher than normal, and is correlated with skin inflammation (13). It also triggers the transcription of miR-21 in epidermal keratinocytes. (11). miR-21-5p is known to downregulate metalloproteinase inhibitor-3 (TIMP-3) in keratinocytes, which is the main tissue inhibitor of the metalloproteinase gene family (14). TIMP-3 inhibits the TNF-converting enzyme, a disintegrin and metalloprotease 17 (ADAM17), which converts the inactive form of TNF into its soluble, activated TNF configuration (15). Binding to the TNF-receptor, the soluble form of TNF, activates the signal transducer and activator of transcription 3 , the transcriptional activator of miR-21 $(14,15)$. The inhibition 


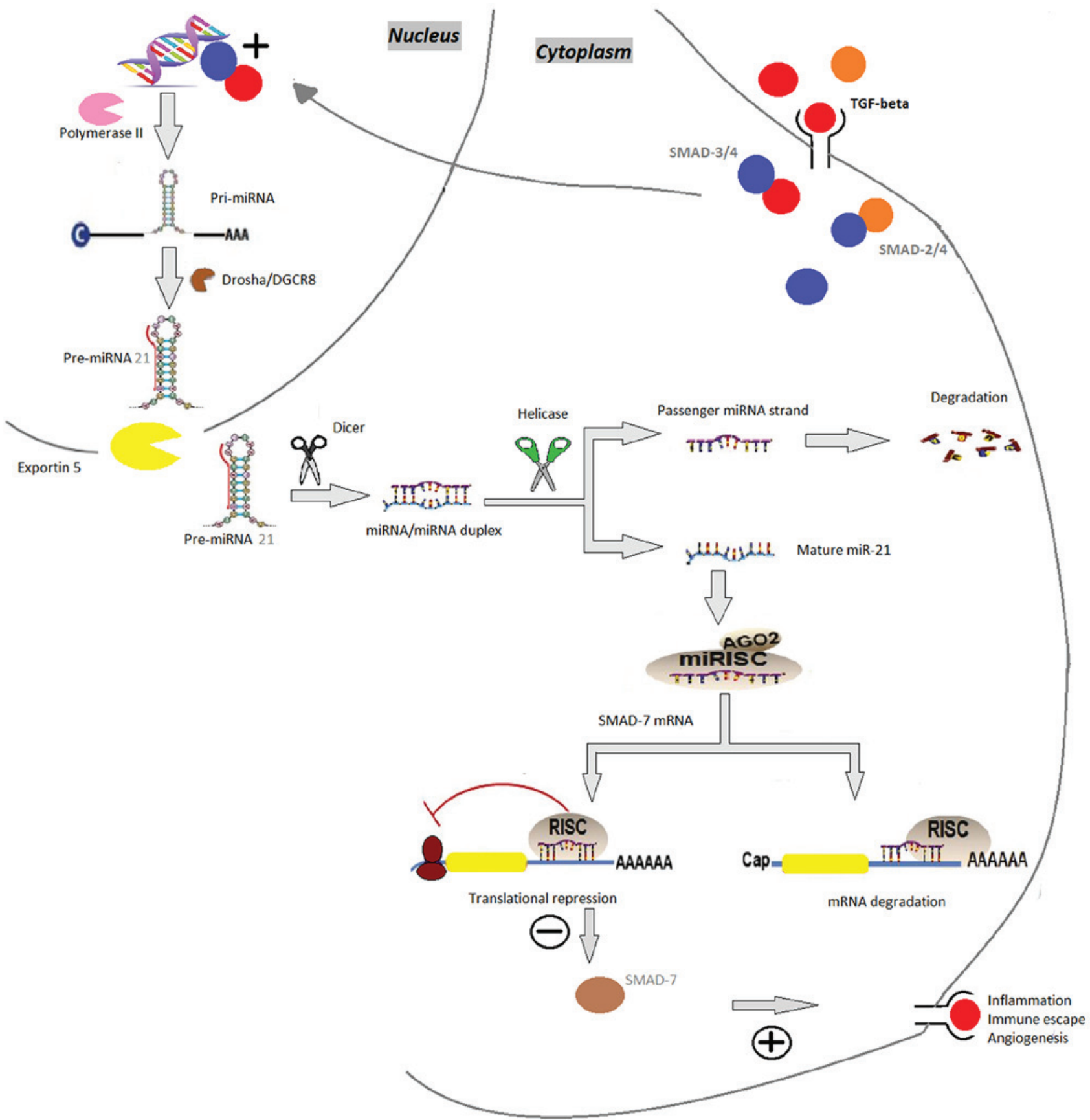

Figure 2. miR-21. TGF- $\beta$ binds to the receptors leading to SMAD-2 or SMAD-3 phosphorylation, followed by aggregation with SMAD-4. SMAD 3/4 appears to induce the transcriptional induction of the synthesis of pri-miR-21, genes which are subsequently processed by Drosha, resulting in pre-miR-21. Pre-miR-21 is then transported by the exportin 5-Ran GTPase shuttle system into the cytoplasm where it is cleaved by another RNase family enzyme (Dicer), resulting miRNA/miRNA duplex. During this phase, Dicer interacts with AGO2 proteins generating the RISC. Immediately following this, one strand of the miRNA duplex is removed while the single stranded miRNA remains in the complex and interacts with the 3 ' untranslated region of target mRNA genes, inducing posttranscriptional silencing and repressing translation of the inhibitory SMAD-7, thereby eliminating the negative feedback mechanism of TGF- $\beta$ signaling. miRNA/miR, microRNA; pri-miR, primary RNA; pre-miR, miRNA precursor; DGCR8, DiGeorge syndrome critical region 8; AGO2, argonaute 2; RISC, RNA-induced silencing complex; TGF- $\beta$, transforming growth factor- $\beta$; SMAD, mothers against decapentaplegic homolog 7.

of miR-21 has been shown to have a beneficial effect in the treatment of psoriasis (15) (Fig. 2).

$m i R-31$. The expression of miR-31 is increased in psoriatic blood and skin samples (16). It enhances nuclear factor $\kappa$-lightchain-enhancer of activated B cells (NF- $\kappa$ B) signaling; NF- $\kappa \mathrm{B}$ is a key mediator in the pathogenesis of psoriasis, involved in various pathways, including inflammation, keratinocyte proliferation, differentiation and apoptosis (17). miR-31 regulates the production of inflammatory mediators (TNF- $\alpha$, IL-1, IL-6, IL-17 and IL-22) and stimulates leukocyte chemotaxis, thus inhibiting miR-31 may be a therapeutic option in psoriasis (18). In this event, the suppression of miR-31 decreases the expression of inflammatory cytokines and chemokines and reduces keratinocyte hyperproliferation (15) (Fig. 3).

miR-146a. miR-146a is increased in psoriatic lesions and peripheral blood mononuclear cells, and during chronic 


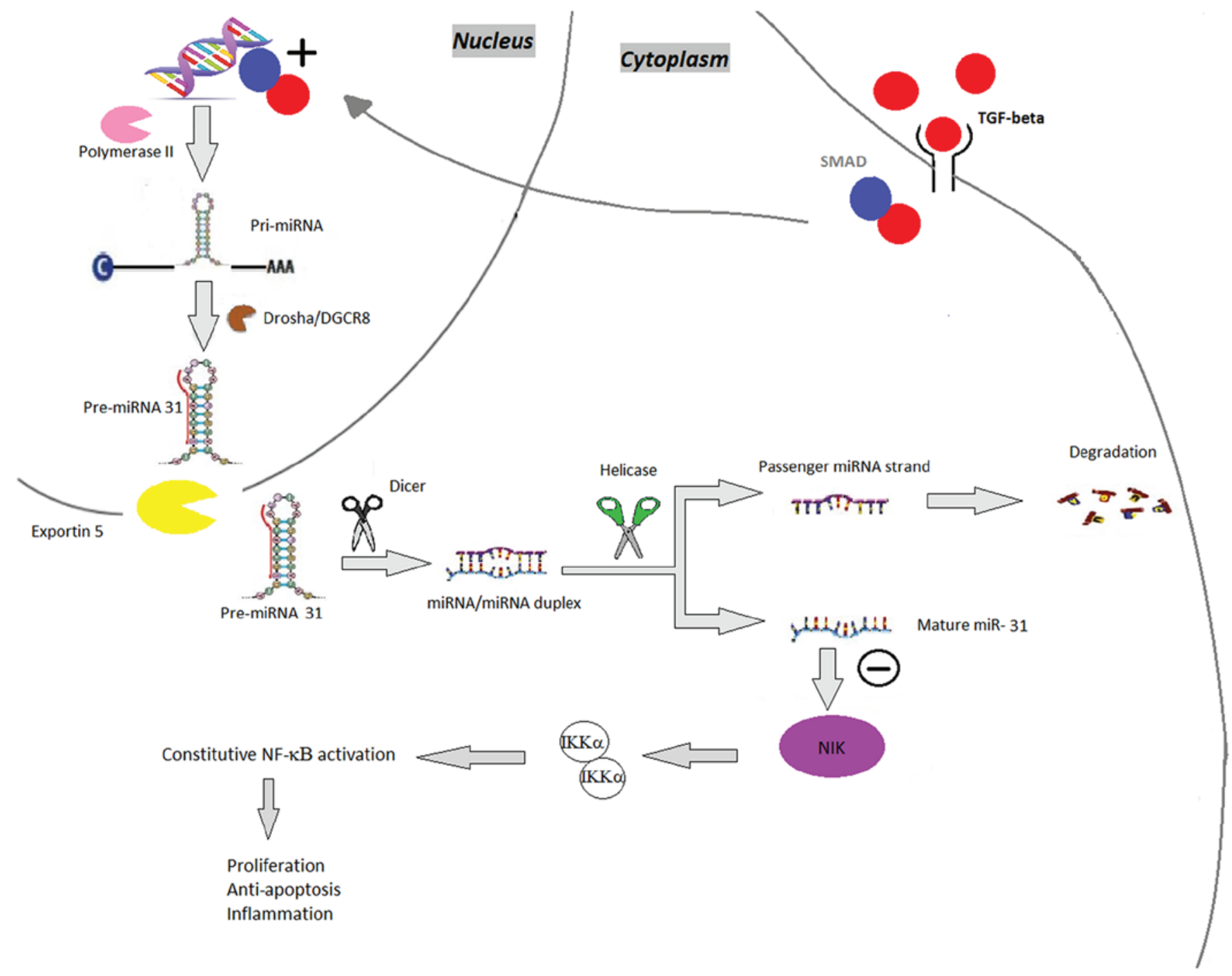

Figure 3. miR-31. TGF- $\beta$ binds to the receptors leading to SMAD phosphorylation, followed by aggregation with SMAD-4, which induces the synthesis of pri-miR-31, which is subsequently processed by Drosha, resulting in pre-miR-31. Pre-miR-31 is then transported by the exportin 5-Ran GTPase shuttle system into the cytoplasm where it is cleaved by another RNase family enzyme (Dicer), resulting in the miRNA/miRNA duplex and, finally, mature miR-31. miR-31 negatively regulates NIK. NIK is involved in phosphorylating IKK $\alpha$ and therefore in controlling the NF- $\mathrm{kB}$ pathway. miRNA/miR, microRNA; pri-miR, primary RNA; pre-miR, miRNA precursor; DGCR8, DiGeorge syndrome critical region 8 ; TGF- $\beta$, transforming growth factor- $\beta$; SMAD, mothers against

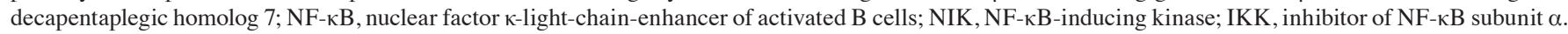

inflammation; it appears to be involved in suppressing the innate immune response in keratinocytes (19-21). Reduced levels of miR-146a cause several effects, among which the early onset of psoriasis, exacerbation of skin inflammation, overexpression of IL-17, and hyperproliferation can be accounted $(20,22)$. According to Pivarsci et al, due to Toll-like receptor (TLR) ligands, miR-146 is persistently increased in keratinocytes, downregulating the expression of inflammatory chemokines including IL-8 and C-C motif chemokine ligand 20 (23). Consequently, miR-146a decreases TLR-dependent epidermal inflammation via the IL-1 receptorassociated kinase-1 and TNF receptor-associated factor 6 pathways, which mediate the IL-17A signaling to NF- $\mathrm{KB}$ and the recruitment of inflammatory cells (24-27) (Fig. 4).

$m i R-155$. The expression of miR-155 is upregulated in psoriatic biopsy samples (15). It is important in processes including cell growth and proliferation (5). By decreasing the expression of IL-4, a cytokine that characterizes the $\mathrm{T}$ helper (Th)2 phenotype, miR-155 promotes differentiation towards a Th1 phenotype $(3,28,29)$. Under such circumstances, during T-cell activation, the expression of miR-155 increases, possibly leading to the abnormal differentiation of $\mathrm{CD}^{+}$ cells into several T-cells subsets in chronic skin inflammation (3). In keratinocytes, miR-155 is induced by TNF- $\alpha$ and IFN- $\gamma(15)$. As a proinflammatory miRNA, via positive feedback, miR-155 increases the production of TNF- $\alpha$ (3). It also targets phosphatase and tensin homolog, which inhibits phosphoinositide 3 -kinase (PI3K) $/ \alpha$-serine/threonine-protein kinase (AKT) signaling, a novel pathway recently identified in association with psoriasis, subsequently enhancing its own effect and maintaining the inflammation in psoriasis (30) (Fig. 5).

$m i R-203$. miR-203 is a skin-specific miRNA, which is exclusively overexpressed in psoriatic keratinocytes and is 


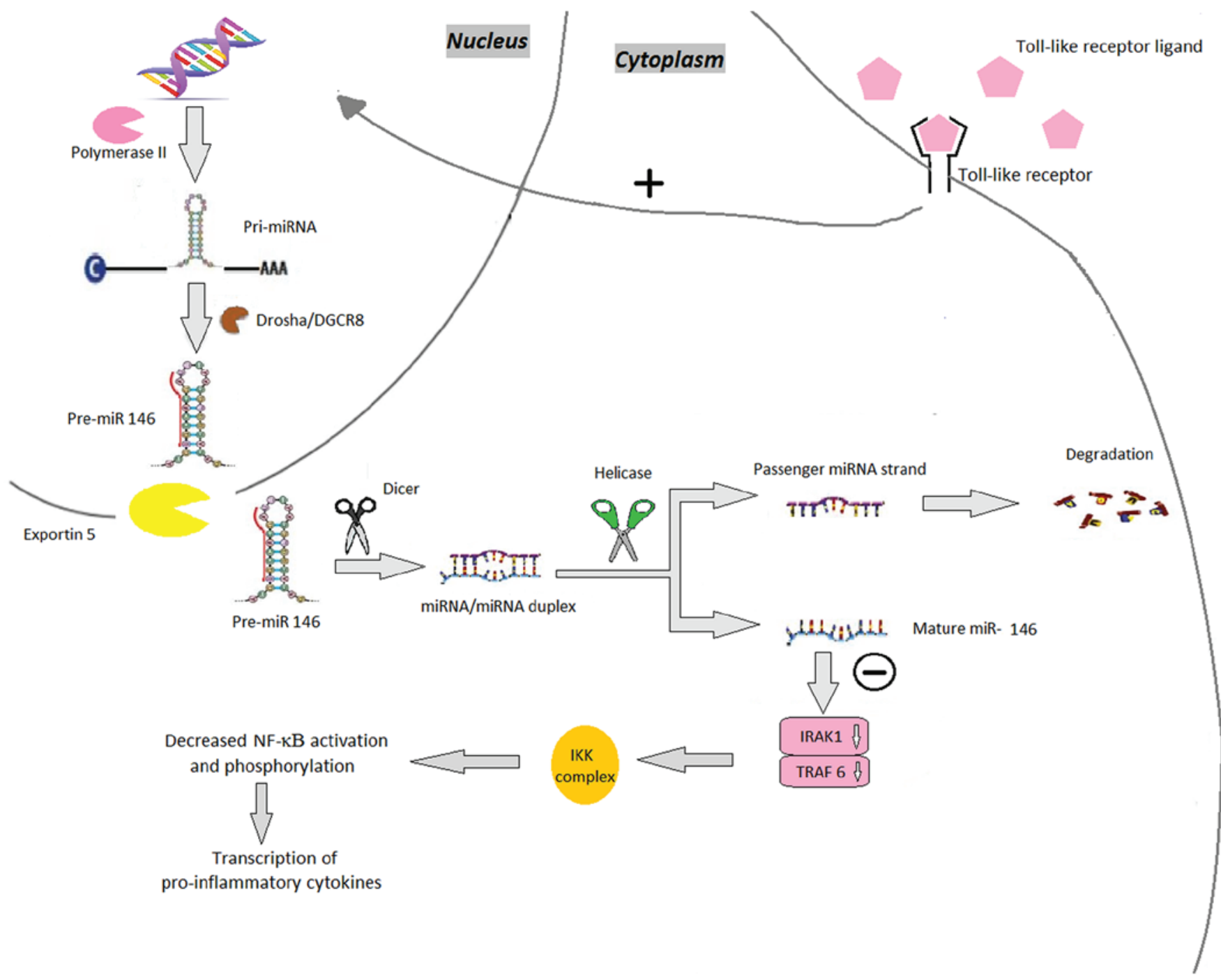

Figure 4. miR-146. Toll-like receptor ligands bind to their receptor increasing the production of pri-miR-146. miR-146 genes are transcribed by RNA polymerase II as pri-miR-146, which are subsequently processed by Drosha, resulting in pre-miR-146. The pre-miR-146 is then transported by the exportin 5-Ran GTPase shuttle system into the cytoplasm where it is cleaved by another RNase family enzyme (Dicer), resulting in the miRNA/miRNA duplex and in the final step, mature miR-146. miR-146 downregulates the expression of TRAF6 and IRAK1. The decreased expression of these modulators leads to decreased phosphorylation of the IKK complex and thereby decreased activation of the NF-kB pathway. miRNA/miR, microRNA; pri-miR, primary RNA; pre-miR, miRNA precursor; DGCR8, DiGeorge syndrome critical region 8; TRAF6, TNF receptor-associated factor 6; IRAK1, interleukin 1 receptor-associated

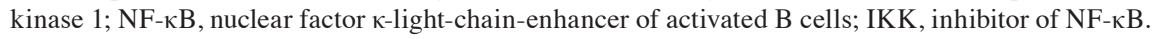

involved in angiogenesis in psoriasis and keratinocyte differentiation (3). Although its role in IL-17-induced vascular endothelial growth factor (VEGF) remains to be fully elucidated, $\mathrm{Xu}$ et al showed that upregulated IL-17 induced the expression of miR-203, which activated the Janus kinase signaling pathway; this promoted the secretion of VEGF in immortalized nontumorigenic human epidermal cells (HaCaT) cells $(31,32)$.

miR-125. miR-125 is found in the blood and skin lesions of patients with psoriasis, and is involved in regulating fibroblast growth factor receptor 2, which suppresses cellular proliferation and prolongs the cellular differentiation of psoriatic keratinocytes (33). In the serum of patients with psoriasis, it appears to be downregulated (5). It appears that inhibiting miR-125 in human keratinocytes may lead to hyperproliferation and delayed cellular differentiation (34). Narrow band UVB phototherapy can increase miR-125 levels significantly (3).
miR-99. miR-99 is specifically downregulated in psoriasis, particularly in keratinocytes and the upper layer of the epidermis (3). It targets IGF-1R, which enhances the proliferation of basal layer cells in patients with psoriasis, stimulating hyperplasia and hyperkeratosis (15). Targeting the IGF-1R mRNA 3' untranslated region (3'UTR), miR-99 decreases the protein levels of IGF-1R, consequently inhibiting keratinocyte proliferation (35). This also causes the cells to differentiate, possibly explaining the higher level of miR-99a detected in the superficial layers of the epidermis (36).

$m i R$-197. Although downregulated in psoriatic skin samples, miR-197 is involved in decreasing proliferation and migration, and driving the differentiation process via normal keratinocytes (5). It binds onto the IL-22RA1 subunit of IL-22, leading to hyperproliferation (37). It can also bind to the IL-17RA subunit of the IL-17R, thus promoting normal proliferation 


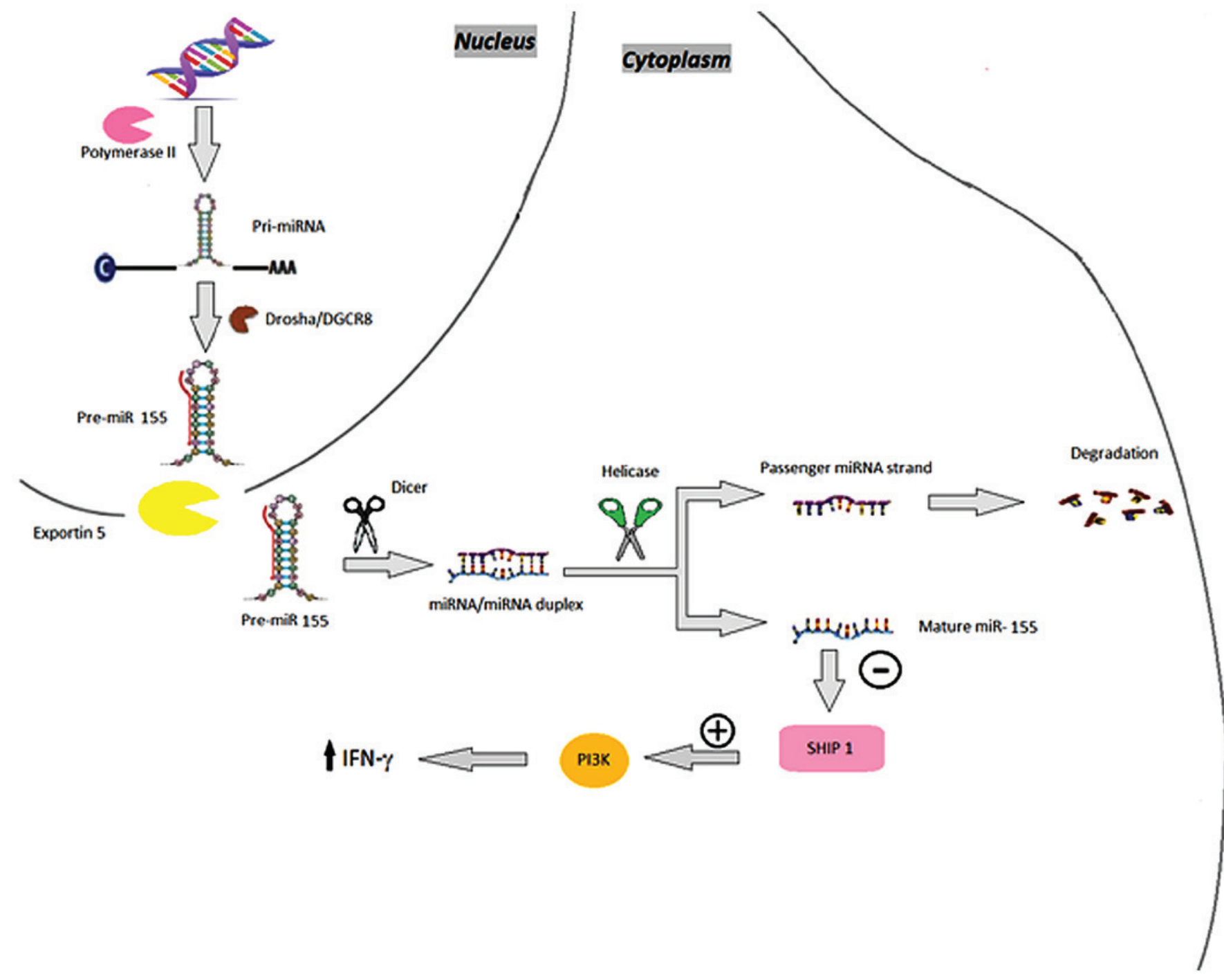

Figure 5. miR-155. miR-155 genes are transcribed by RNA polymerase II as pri-miR-155, which are subsequently processed by Drosha, resulting in premiR-155. Pre-miR-155 is then transported by the exportin 5-Ran GTPase shuttle system into the cytoplasm where it is cleaved by another RNase family enzyme (Dicer), resulting in the miRNA/miRNA duplex and, finally, mature miR-155 that targets the 5' inositol phosphatase SHIP1, which downregulates its expression and, in turn, promotes sustained activation of the PI3K pathway, consequently enhancing the production of IFN- $\gamma$. miRNA/miR, microRNA; pri-miR, primary RNA; pre-miR, miRNA precursor; DGCR8, DiGeorge syndrome critical region 8; SHIP1, SH-2 containing inositol polyphosphatase 1; PI3K, phosphoinositide 3-kinase; IFN- $\gamma$; interferon- $\gamma$.

and decreasing the process of abnormal differentiation (38). By inhibiting IL-17RA in keratinocytes, miR-197 reduces the expression of CCL, a chemoattractant for dendritic cells and $\mathrm{T}$ lymphocytes (37).

$m i R-520 . m i R-520$ is found in psoriatic keratinocytes and is markedly downregulated (10). In vitro experiments on $\mathrm{HaCaT}$ cells have confirmed the importance of miR-520 in the proliferation and mitosis of human keratinocytes (39). In vitro, it markedly suppressed the proliferation and mitotic entry of HaCaT cells by inhibiting AKT (40). miR-520a downregulates the transcription factor E2F, which suppresses cell cycle progression and proliferation (39). It also binds to the 3'UTR of AKT1 mRNA, thus inhibiting keratinocyte proliferation (40). Although utilizing miR-520 as a treatment option for psoriatic patients remains a challenge, the problem may be solved by using mimics of miRNA-520 (40).

\section{Conclusion}

In the present review, various examples of miRNA involvement in psoriasis are described (Table I). miRNAs can be detected in small volume blood samples or skin samples using quantitative realtime polymerase chain reaction (41). A promising characteristic is that miRNAs can be used in psoriasis for diagnosis, prognosis or as a treatment option (5). Multiple interactions between epidermal keratinocytes and immunocytes generally lead to the development of this disease (15). A considerable number of miRNAs have been described to be upregulated in psoriasis, thus their inhibition may offer a revolutionary treatment method (42). Therefore, the increased miRNAs require downregulation using miRNA inhibitors, whereas miRNAs that are decreased in psoriasis require supplementation using miRNA mimics (43).

In conclusion, further investigations are likely to confirm the advantages of using miRNAs in psoriasis as a biomarker, prognostic marker or novel treatment option. 
Table I. Characteristics of miRNAs in psoriasis.

\begin{tabular}{|c|c|c|c|}
\hline miRNA & Level & Sites found & Effects \\
\hline $\operatorname{miR}-21$ & Upregulated & $\begin{array}{l}\text { Skin lesions, psoriasis epidermal } \\
\text { cells, dermal T cells } \\
\text { Blood samples }\end{array}$ & $\begin{array}{l}\text { Inflammation } \\
\text { Immune evasion } \\
\text { Angiogenesis }\end{array}$ \\
\hline $\operatorname{miR}-31$ & Upregulated & $\begin{array}{l}\text { Skin samples } \\
\text { Blood samples }\end{array}$ & $\begin{array}{l}\text { Enhances the production of inflammatory } \\
\text { cytokines and chemokines }\end{array}$ \\
\hline $\operatorname{miR}-146$ & Upregulated & $\begin{array}{l}\text { Psoriasis lesions } \\
\text { Peripheral blood mononuclear cells }\end{array}$ & $\begin{array}{l}\text { Maintains chronic inflammation } \\
\text { Recruitment of inflammatory cells }\end{array}$ \\
\hline miR-155 & Upregulated & Biopsy samples & $\begin{array}{l}\text { Pro-inflammatory, increases the production } \\
\text { of tumor necrosis factor- } \alpha\end{array}$ \\
\hline $\operatorname{miR}-203$ & Upregulated & Psoriasis lesions & $\begin{array}{l}\text { Induces epithelial differentiation and } \\
\text { suppresses skin immune responses }\end{array}$ \\
\hline $\operatorname{miR}-125$ & Downregulated & $\begin{array}{l}\text { Skin lesions } \\
\text { Blood samples }\end{array}$ & $\begin{array}{l}\text { Via fibroblast growth factor receptor } 2 \text {, } \\
\text { suppresses cell proliferation } \\
\text { Prolongs differentiation of psoriatic keratinocytes }\end{array}$ \\
\hline miR-99 & Downregulated & $\begin{array}{l}\text { Keratinocytes, upper } \\
\text { layer of epidermis }\end{array}$ & $\begin{array}{l}\text { By targeting insulin-like growth factor } 1 \text { receptor, } \\
\text { inhibits keratinocyte proliferation and drives them } \\
\text { towards differentiation }\end{array}$ \\
\hline miR-197 & Downregulated & Skin samples & $\begin{array}{l}\text { Decreases the proliferation and } \\
\text { migration of keratinocytes }\end{array}$ \\
\hline $\operatorname{miR}-520$ & Downregulated & $\begin{array}{l}\text { Keratinocytes } \\
\text { Cell cultures }\end{array}$ & $\begin{array}{l}\text { Suppresses the mitotic entry and } \\
\text { proliferation of keratinocytes }\end{array}$ \\
\hline
\end{tabular}

miR, microRNA.

\section{Acknowledgements}

The authors would like to acknowledge Dr Ioan Alexandru Florian at the Department of Neurosurgery, Cluj County Emergency Hospital, Cluj-Napoca, Romania, for his assistance in editing and revising the manuscript.

\section{Funding}

No funding was received.

\section{Availability of data and materials}

Not applicable.

\section{Authors' contributions}

Both authors were equally involved in the conception and design of the article, as well as in writing and revising the manuscript. Both authors gave final approval of the version to be published and have agreed to be accountable for all aspects of the work in ensuring that questions related to the accuracy or integrity of any part of the work are appropriately investigated and resolved. TLT gathered data and drafted the manuscript regarding the upregulated miRNAs and provided the illustrations and table. RIO gathered data and drafted the manuscript regarding the downregulated miRNAs.

\section{Ethics approval and consent to participate}

Not applicable.

\section{Consent for publication}

Not applicable.

\section{Competing interests}

The authors declare that they have no competing interests.

\section{References}

1. Nestle FO, Kaplan DH and Barker J: Psoriasis. N Engl J Med 361: 496-509, 2009.

2. Gudjonsson JE and Elder JT: Psoriasis: Epidemiology. Clin Dermatol 25: 535-546, 2007.

3. Huang RY, Li L, Wang MJ, Chen XM, Huang QC and Lu CJ: An Exploration of the role of MicroRNAs in psoriasis: A systematic review of the literature. Medicine (Baltimore) 94: e2030, 2015.

4. Ortega C, Fernández-A S, Carrillo JM, Romero P, Molina IJ, Moreno JC and Santamaría M:IL-17-producing CD8 ${ }^{+}$Tlymphocytes from psoriasis skin plaques are cytotoxic effector cells that secrete Th17-related cytokines. J Leukoc Biol 86: 435-443, 2009.

5. Ross K: Towards topical microRNA-directed therapy for epidermal disorders. J Control Release 269: 136-147, 2018.

6. Soltanzadeh-Yamchi M, Shahbazi M, Aslani S and Mohammadnia-Afrouzi M: MicroRNA signature of regulatory $\mathrm{T}$ cells in health and autoimmunity. Biomed Pharmacother 100: 316-323, 2018. 
7. Ruksha TG, Komina AV and Palkina NV: MicroRNA in skin diseases. Eur J Dermatol 27: 343-352, 2017.

8. Liu Y and Liu Q: MicroRNAs as regulatory elements in psoriasis. Open Med (Wars) 11: 336-340, 2016.

9. Barca-Mayo O and Lu QR: Fine-tuning oligodendrocyte development by microRNAs. Front Neurosci 6: 13, 2012.

10. Hawkes JE, Nguyen GH, Fujita M, Florell SR, Callis Duffin K, Krueger GG and O'Connell RM: microRNAs in psoriasis. J Invest Dermatol 136: 365-371, 2016.

11. Jiang M, Sun Z, Dang E, Li B, Fang H, Li J, Gao L, Zhang K and Wang G: TGF $\beta / \mathrm{SMAD} /$ microRNA-486-3p signaling axis mediates keratin 17 expression and keratinocyte hyperproliferation in psoriasis. J Invest Dermatol 137: 2177-2186, 2017.

12. Degueurce G, D'Errico I, Pich C, Ibberson M, Schütz F, Montagner A, Sgandurra M, Mury L, Jafari P, Boda A, et al: Identification of a novel PPAR $\beta / \delta / \mathrm{miR}-21-3 p$ axis in UV-induced skin inflammation. EMBO Mol Med 8: 919-936, 2016.

13. Boele J, Persson H, Shin JW, Ishizu Y, Newie IS, Søkilde R, Hawkins SM, Coarfa C, Ikeda K, Takayama $\mathrm{K}$, et al: PAPD5-mediated 3' adenylation and subsequent degradation of miR-21 is disrupted in proliferative disease. Proc Natl Acad Sci USA 111: 11467-11472, 2014.

14. Guinea-Viniegra J, Jiménez M, Schonthaler HB, Navarro R, Delgado Y, Concha-Garzón MJ, Tschachler E, Obad S, Daudén E and Wagner EF: Targeting miR-21 to treat psoriasis. Sci Transl Med 6: 225re1, 2014.

15. Masalha M, Sidi Y and Avni D: The contribution of feedback loops between miRNAs, cytokines and growth factors to the pathogenesis of psoriasis. Exp Dermatol 27: 603-610, 2018.

16. Stepicheva NA and Song JL: Function and regulation of microRNA-31 in development and disease. Mol Reprod Dev 83: 654-674, 2016

17. Yan S, Xu Z, Lou F, Zhang L, Ke F, Bai J, Liu Z, Liu J, Wang H, Zhu $\mathrm{H}$, et al: NF- $\kappa \mathrm{B}$-induced microRNA-31 promotes epiderma hyperplasia by repressing protein phosphatase 6 in psoriasis. Nat Commun 6: 7652, 2015.

18. Xu N, Meisgen F, Butler LM, Han G, Wang XJ, SöderbergNauclér C, Ståhle M, Pivarcsi A and Sonkoly E: MicroRNA-31 is overexpressed in psoriasis and modulates inflammatory cytokine and chemokine production in keratinocytes via targeting serine/threonine kinase 40. J Immunol 190: 678-688, 2013.

19. Hermann H, Runnel T, Aab A, Baurecht H, Rodriguez E, MagilnickN,Urgard E, Šahmatova L, Prans E, Maslovskaja J, et al: miR-146b probably assists miRNA-146a in the suppression of keratinocyte proliferation and inflammatory responses in psoriasis. J Invest Dermatol 137: 1945-1954, 2017.

20. Ichihara A,Jinnin M, Yamane K, Fujisawa A, Sakai K, MasuguchiS, Fukushima S, Maruo K and Ihn H: microRNA-mediated keratinocyte hyperproliferation in psoriasis vulgaris. Br J Dermatol 165: 1003-1010, 2011

21. Zibert JR, Løvendorf MB, Litman T, Olsen J, Kaczkowski B and Skov L: MicroRNAs and potential target interactions in psoriasis. J Dermatol Sci 58: 177-185, 2010.

22. Srivastava A, Nikamo P, Lohcharoenkal W, Li D, Meisgen F, Xu Landén N,Ståhle M,Pivarcsi A and Sonkoly E: MicroRNA-146a suppresses IL-17-mediated skin inflammation and is genetically associated with psoriasis. J Allergy Clin Immunol 139: 550-561, 2017.

23. Pivarcsi A, Ståhle M and Sonkoly E: Genetic polymorphisms altering microRNA activity in psoriasis - a key to solve the puzzle of missing heritability? Exp Dermatol 23: 620-624, 2014.

24. Guo Q, Zhang J, Li J, Zou L, Zhang J, Xie Z, Fu X, Jiang S, Chen G, Jia Q, et al: Forced miR-146a expression causes autoimmune lymphoproliferative syndrome in mice via downregulation of Fas in germinal center B cells. Blood 121: 4875-4883, 2013

25. Xia P, Fang X, Zhang ZH, Huang Q, Yan KX, Kang KF, Han L and Zheng ZZ: Dysregulation of miRNA146a versus IRAK1 induces IL-17 persistence in the psoriatic skin lesions. Immunol Lett 148: 151-162, 2012.

26. Chatzikyriakidou A, Voulgari PV, Georgiou I and Drosos AA: The role of microRNA-146a (miR-146a) and its target IL-1Rassociated kinase (IRAK1) in psoriatic arthritis susceptibility. Scand J Immunol 71: 382-385, 2010.
27. Shams K, Kurowska-Stolarska M, Schütte F, Burden AD, McKimmie CS and Graham GJ: MicroRNA-146 and cell trauma down-regulate expression of the psoriasis-associated atypical chemokine receptor ACKR2. J Biol Chem 293: 3003-3012, 2018.

28. Hou RX, Liu RF, Zhao XC, Jia YR, An P, Hao ZP, Li JQ, Li XH, Yin $\mathrm{GH}$ and Zhang KM: Increased miR-155-5p expression in dermal mesenchymal stem cells of psoriatic patients: Comparing the microRNA expression profile by microarray. Genet Mol Res: Sep 2, 2016 (Epub ahead of print). doi: 10.4238/gmr.15038631.

29. García-Rodríguez S, Arias-Santiago S, Blasco-Morente G, Orgaz-Molina J, Rosal-Vela A, Navarro P, Magro-Checa C, Martínez-López A, Ruiz JC, Raya E, et al: Increased expression of microRNA-155 in peripheral blood mononuclear cells from psoriasis patients is related to disease activity. J Eur Acad Dermatol Venereol 31: 312-322, 2017.

30. Xu L, Leng H, Shi X, Ji J, Fu J and Leng H: miR-155 promotes cell proliferation and inhibits apoptosis by PTEN signaling pathway in the psoriasis. Biomed Pharmacother 90: 524-530, 2017.

31. Xu Y, Ji Y, Lan X, Gao X, Chen HD and Geng L: miR 203 contributes to IL 17 induced VEGF secretion by targeting SOCS3 in keratinocytes. Mol Med Rep 16: 8989-8996, 2017.

32. Primo MN, Bak RO, Schibler B and Mikkelsen JG: Regulation of pro-inflammatory cytokines TNF $\alpha$ and IL24 by microRNA-203 in primary keratinocytes. Cytokine 60: 741-748, 2012.

33. Xu N, Brodin P, Wei T, Meisgen F, Eidsmo L, Nagy N, Kemeny L, Ståhle M, Sonkoly E and Pivarcsi A: miR-125b, a microRNA downregulated in psoriasis, modulates keratinocyte proliferation by targeting FGFR2. J Invest Dermatol 131: 1521-1529, 2011.

34. Wei T, Folkersen L, Biskup E, Xu N, Manfe V, Niazi O and Gniadecki R: Ubiquitin-specific peptidase 2 as a potential link between microRNA-125b and psoriasis. Br J Dermatol 176: 723-731, 2017.

35. Wang MJ, Xu YY, Huang RY, Chen XM, Chen HM, Han L, Yan YH and Lu CJ: Role of an imbalanced miRNAs axis in pathogenesis of psoriasis: Novel perspectives based on review of the literature. Oncotarget 8: 5498-5507, 2017.

36. Lerman G, Avivi C,Mardoukh C, Barzilai A, Tessone A, Gradus B, Pavlotsky F, Barshack I, Polak-Charcon S, Orenstein A, et al: miRNA expression in psoriatic skin: Reciprocal regulation of hsa-miR-99a and IGF-1R. PLoS One 6: e20916, 2011.

37. Lerman G, Sharon M, Leibowitz-Amit R, Sidi Y and Avni D: The crosstalk between IL-22 signaling and miR-197 in human keratinocytes. PLoS One 9: e107467, 2014.

38. Elharrar E, Masalha M, Lerman G, Leibowitz-Amit R, Kassem R, Harats M, Sidi Y and Avni D: Positive-negative feedback loop between MiR-197 and IL-17A signaling in human keratinocytes. Immunome Res: May 2, 2016 (Epub ahead of print). doi: 10.4172/1745-7580.10000111.

39. Wang R, Zhao Z, Zheng L, Xing X, Ba W, Zhang J, Huang M, Zhu W, Liu B, Meng X, et al: MicroRNA-520a suppresses the proliferation and mitosis of $\mathrm{HaCaT}$ cells by inactivating protein kinase B. Exp Ther Med 14: 6207-6212, 2017.

40. Wang X, Wang P, Zhu Y, Zhang Z, Zhang J and Wang $\mathrm{H}$ : MicroRNA-520a attenuates proliferation of Raji cells through inhibition of AKT1/NF- $\kappa \mathrm{B}$ and PERK/eIF2 $\alpha$ signaling pathway. Oncol Rep 36: 1702-1708, 2016.

41. Van Gele M, Bracke S, Alves de Medeiros AK and Lambert J: Exploring the feasibility of whole blood to identify systemic miRNA biomarkers for patients with moderate to severe psoriasis. Eur J Dermatol 26: 195-198, 2016.

42. Liu Q, Wu DH, Han L, Deng JW, Zhou L, He R, Lu CJ and Mi QS: Roles of microRNAs in psoriasis: Immunological functions and potential biomarkers. Exp Dermatol 26: 359-367, 2017.

43. Sonkoly E, Wei T, Janson PC, Sääf A, Lundeberg L, Tengvall-Linder M, Norstedt G, Alenius H, Homey B, Scheynius A, et al: MicroRNAs: Novel regulators involved in the pathogenesis of psoriasis? PLoS One 2: e610, 2007.

This work is licensed under a Creative Commons Attribution-NonCommercial-NoDerivatives 4.0 International (CC BY-NC-ND 4.0) License. 